\title{
Synthesis and Characterization of Polymers Containing Tin and Transition Metals in the Main Chain
}

\author{
Tadasu TAHARA, Koji Seto, and Shigetoshi TAKAHASHI* \\ Research \& Development Division, Nitto Kasei Co., \\ 3 Nishiawaji, Higashiyodogawa-ku, Osaka 533, Japan \\ *The Institute of Scientific and Industrial Research, \\ Osaka University, Ibaraki, Osaka 567, Japan
}

(Received October 16, 1986)

\begin{abstract}
Organometallic polymers containing tin and transition metals have been synthesized by polycondensation between dimethyldi(4-ethynylphenyl)tin and transition metal halides using cuprous iodide as a catalyst in diethylamine. The polymers, in which tin and transition metals are regularly linked by a conjugated system through $\mathbf{M}-\mathbf{C}$ bonds, are characterized by spectral analyses.

KEY WORDS Organometallic Polymer / Tin Polymer / Palladium

Polymer / Platinum Polymer / Poly(yne) Polymer /
\end{abstract}

In recent years a wide variety of polymers containing metal atoms have been prepared in terms of their potential catalytic activities and physical properties. ${ }^{1}$ Among them organotin polymers are of special interest and have found wide application as, for example, antifouling materials. Most of the tin polymers have tin atoms bonded to oxygen or nitrogen atom in a side chain or sometimes in the main chain of polymers. ${ }^{2}$ On the other hand, there have been few examples of polymers in which tin atoms are joined in a main chain by tin-carbon sigma bond. Although the $\sigma$-bond between tin and carbon may be expected to be stable enough to compose a polymer backbone, luck of the suitable method being applicable to the polymerization of tin monomers seems to result in limitation of the known examples of such polymers. Application of hydrostannylation to $\alpha, \omega$-diolefins has been shown ${ }^{3}$ to give polymers having a structure of $\mathrm{fR}_{2} \mathrm{Sn}-\mathrm{CH}_{2} \mathrm{CH}_{2}-$ $\left.\mathrm{Y}-\mathrm{CH}_{2} \mathrm{CH}_{2}\right]_{n}$.

We previously showed that polycondensa-

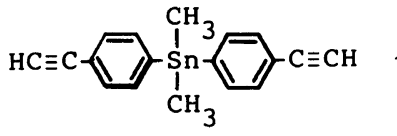

I<smiles>CCN(C)C(C)(Cl)CC</smiles>

II

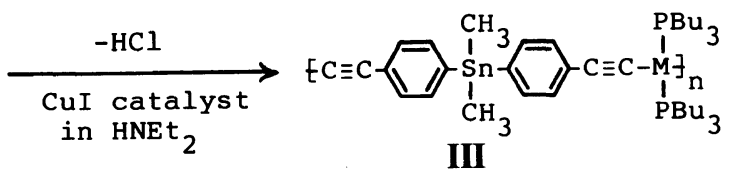

a: $\quad M=P t$

b: $\quad \mathbf{M}=\mathbf{P d}$ 
tion between transition metal dihalides and $\alpha,(1)$-diynes smoothly proceeds in the presence of a copper(I) catalyst in amines to give highmolecular-weight poly(yne) polymers containing metals in the polymer main chain. ${ }^{4}$ Now we report the use of this method for synthesis of organotin polymers in which tin and transition metals are linked by a conjugated system through $\mathrm{M}-\mathrm{C} \sigma$-bonds and are arranged regularly in the polymer main chain.

\section{EXPERIMENTAL}

\section{Synthesis of Polymer III}

In a typical experiment cuprous iodide $(5 \mathrm{mg})$ was added to a deoxygenated solution of dimethyldi(ethynylphenyl)tin (I, $351.0 \mathrm{mg}, 1.0 \mathrm{mmol}$ ) and cis-dichlorobis(trin-butylphosphine)platinum (IIa, $670.2 \mathrm{mg}$, $1.0 \mathrm{mmol}$ ) in $80 \mathrm{ml}$ of diethylamine. The mixture was stirred under reflux for $24 \mathrm{~h}$ in a nitrogen atomosphere, and then evaporated until dry under reduced pressure. The residue was dissolved in benzene and filtered by a short alumina column. After evaporation of the filtrate, a yellow product was collected and purified by precipitation from benzene to methanol. Finally, a benzene solution of the product was frozen and then freeze dried under reduced pressure to give a yellow polymer of $\left\{\mathrm{C} \equiv \mathrm{C}-\mathrm{C}_{6} \mathrm{H}_{4}-\mathrm{Sn}\left(\mathrm{CH}_{3}\right)_{2}-\mathrm{C}_{6} \mathrm{H}_{4}-\mathrm{C} \equiv\right.$ $\left.\mathrm{C}-\mathrm{Pt}\left(\mathrm{PBu}_{3}\right)_{2}\right]_{n}$ (IIIa) in $60 \%$ yield, [ $\left.\eta\right], 0.23$ $\mathrm{dlg}^{-1}$ (in THF at $25^{\circ} \mathrm{C}$ ); $\bar{M}_{w}, 27,000$ (GPC method; mobile phase, THF). ${ }^{5}$ Anal. Calcd for $\left(\mathrm{C}_{42} \mathrm{H}_{68} \mathrm{P}_{2} \mathrm{SnPt}\right)_{n}$ : C, 53.17\%; H, 7.22\%; $\mathrm{P}, 6.52 \%$. Found: C, $53.33 \%$; H, 7.25\%; P, $6.33 \%$.

Similarly, condensation between $\mathbf{I}$ and trans-dichlorobis(tri- $n$-butylphosphine)palladium was carried out at room temperature for $18 \mathrm{~h}$, giving polymer IIIb $(\mathbf{M}=\mathbf{P d})$ as a pale yellow solid in $71 \%$ yield, $\bar{M}_{w}, 23,000$. Anal. Calcd for $\left(\mathrm{C}_{42} \mathrm{H}_{68} \mathrm{P}_{2} \mathrm{SnPd}\right)_{n}$ : C, $58.65 \%$; $\mathrm{H}, 7.96 \%$; P, $7.20 \%$. Found: C, $59.31 \%$; $7.55 \% ; \mathrm{P}, 6.49 \%$.

\section{Synthesis of Polymer IV}

A mixture of $\mathbf{I}$ and $p$-diiodobenzene in diethylamine $(100 \mathrm{ml})$ and THF $(20 \mathrm{ml})$ was stirred in the presence of catalytic amounts of cuprous iodide $(15 \mathrm{mg}$ ) and dichlorobis(triphenylphosphine)palladium (28 mg) under reflux. After $5 \mathrm{~h}$ the reaction mixture was poured into methanol $(200 \mathrm{ml})$, and the resultant precipitate was collected. The product was washed thoroughly with hot toluene and dried at $60^{\circ} \mathrm{C}$ in vacuum, giving polymer IVa as a yellow solid in $86 \%$ yield. Anal. Calcd for $\left(\mathrm{C}_{18} \mathrm{H}_{24} \mathrm{Sn}\right)_{9} \mathrm{C}_{6} \mathrm{H}_{4} \mathrm{I}_{2}: \mathrm{C}, 63.59 \% ; \mathrm{H}, 4.00 \%$; I, $6.22 \%$. Found: C, $63.92 \%$; H, $4.16 \%$; $6.33 \%$.

\section{Synthesis of Polymer $\mathbf{V}$}

Oxygen was passed into a mixture of cuprous chloride $(1.2 \mathrm{~g}, 12 \mathrm{mmol})$ and $N, N$, $N^{\prime}, N^{\prime}$-tetramethylethylenediamine $(1.6 \mathrm{~g}, 14$ $\mathrm{mmol}$ ) in $160 \mathrm{ml}$ of dichloromethane for 20 min at room temperature. To the resultant green oxidant, a solution of I $(1.0 \mathrm{~g}, 2.9$ $\mathrm{mmol})$ in dichloromethane $(80 \mathrm{ml})$ was added at once and stirred vigorously at room temperature for $24 \mathrm{~h}$. The polymer precipitated during the reaction was collected and washed thoroughly with water, methanol, and then with hot toluene. Drying at $100^{\circ} \mathrm{C}$ in vacuum afforded polymer $\mathbf{V}, € \mathrm{C} \equiv \mathrm{C}$ $\mathrm{C}_{6} \mathrm{H}_{4}-\mathrm{Sn}\left(\mathrm{CH}_{3}\right)_{2}-\mathrm{C}_{6} \mathrm{H}_{4}-\mathrm{C} \equiv \mathrm{C}_{n}$, as pale greenish yellow solids in an almost quantitative yield. Anal. Calcd for $\left(\mathrm{C}_{18} \mathrm{H}_{14} \mathrm{Sn}\right)_{n}$ : C, $61.95 \% ; \mathrm{H}, 4.04 \%$. Found: C, $60.42 \% ; \mathrm{H}$, $4.23 \%$.

\section{RESULTS AND DISCUSSION}

Previously, for the synthesis of transition metal-poly(yne) polymers, we employed bis(acetylide) complexes of the type $\left(\mathrm{R}_{3} \mathrm{P}\right)_{2} \mathrm{M}$ $(\mathrm{C} \equiv \mathrm{C}-\mathrm{Y}-\mathrm{C} \equiv \mathrm{CH})_{2}$ as a co-monomer in the polycondensation catalyzed by a cuprous halide. ${ }^{5}$ In the case of tin analogues, however, the bond $\mathrm{Sn}-\mathrm{C} \equiv$ in tin-bis(acetylide) is readily cleaved by the action of even weak acids due 
to the ionic character of the bond. Therefore, polymers containing such a bond may be unstable and cannot be purified by means such as chromatography on alumina. For this reason tin compounds having the $-\mathrm{C} \equiv \mathrm{C}-$ $\mathrm{Sn}-\mathrm{C} \equiv \mathrm{C}-$ bond such as $\mathrm{R}_{2} \mathrm{Sn}(\mathrm{C} \equiv \mathrm{CH})_{2}$ and $\mathrm{R}_{2} \mathrm{Sn}\left(\mathrm{C} \equiv \mathrm{C}-\mathrm{C}_{6} \mathrm{H}_{4}-\mathrm{C} \equiv \mathrm{CH}\right)_{2}$ may beunsuitable as monomers for the polycondensation. On the other hand, the bond $\mathrm{Sn}-\mathrm{C}_{\mathrm{sp}^{2}}$ is stable enough to form polymers, and we chose a 4-ethynylphenyl-tin compound (I) as the co-monomer for the condensation with a transition metal dihalide. Since the compound I exhibited a reactivity comparable to $p$-diethynylbenzene for the copper(I) catalyzed condensation with transition metal halides, the polymerization reaction was carried out under the same conditions as those employed previously. ${ }^{5}$

In the presence of the cuprous iodide catalyst, the condensation between I and platinum dihalide IIa proceeded smoothly in diethylamine under reflux to give a $\mathrm{Sn}-\mathrm{Pt}$ polymer having a structure of IIIa in a good yield, whereas condensation of I with palladium dihalide IIa was accomplished at room temperature because of the higher reactivity of the halide.

The polymers IIIa and IIIb are soluble in common organic solvents such as benzene, toluene, tetrahydrofuran, and dichloromethane except alcohols. The Sn-Pt polymer IIIa is stable in air both in the solid state and in solutions, and the thermogravimetric analysis showed it to be thermally stable up to $300^{\circ} \mathrm{C}$ in vacuum. The $\mathrm{Sn}-\mathrm{Pd}$ polymer IIIb is relatively unstable in air, especially in solutions and thermally decomposed at $185^{\circ} \mathrm{C}$. The sigma bond between palladium and carbon is generally recognized to be less stable than the $\mathrm{Pt}-\mathrm{C}$ bond. The stability of the polymers, therefore, seems to be affected by not the tin moiety but the transition metal moiety in the polymer backbone.

We also synthesized organotin polymers IV and V. Previously we showed the palladium-copper system to catalyze a C-C coupling between ethynyl compounds and haloarenes to give ethynylarenes in high yields. ${ }^{6}$ This reaction has been used for the synthesis of polymer IV. Thus, in the presence
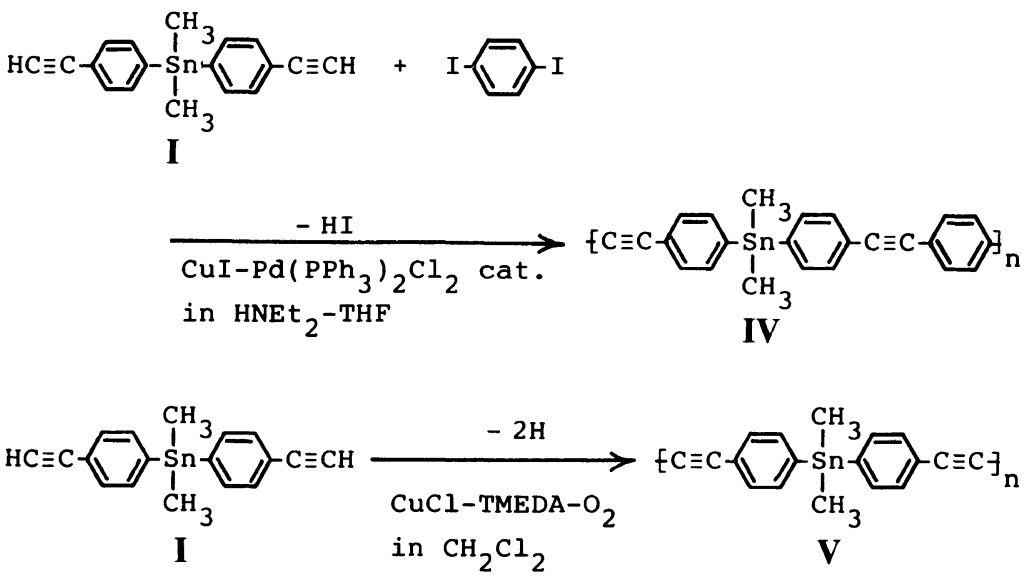

of catalytic amounts of palladium(II) and coppper(I) the tin compound I underwent polycondensation with $p$-diiodobenzene in an amine to afford polymer IV in a good yield. The polymer was obtained as orange solids. The analytical data indicated that the polymer has iodine as the terminal group, and the absence of ethynyl groups suggests the structure IVa ( $n=9$ from the elemental analysis). 
Table I. Spectral data of the polymers

\begin{tabular}{|c|c|c|c|c|c|c|}
\hline \multirow{2}{*}{ Polymer } & \multirow{2}{*}{$\begin{array}{c}{ }^{1} \mathrm{H} \text { NMR, } \\
\delta / \mathrm{ppm}\end{array}$} & \multirow{2}{*}{$\begin{array}{l}{ }^{31} \mathrm{P} \text { NMR, } \\
\delta / \mathrm{ppm}\end{array}$} & \multirow{2}{*}{$\begin{array}{c}\mathrm{IR}, \\
v_{\mathrm{C} \equiv \mathrm{C}} / \mathrm{cm}^{-1}\end{array}$} & \multicolumn{2}{|c|}{$\begin{array}{c}\mathrm{ESCA} / \mathrm{eV}^{\mathrm{b}} \\
\mathrm{Sn}\end{array}$} & \multirow{2}{*}{$\begin{array}{l}\mathrm{UV} / \mathrm{nm}^{\mathrm{c}} \\
\lambda_{\max } / \log \varepsilon\end{array}$} \\
\hline & & & & $3 d_{5 / 2}$ & $3 d_{3 / 2}$ & \\
\hline I & $\begin{array}{l}0.52\left(\mathrm{Sn}-\mathrm{CH}_{3}\right) \\
3.08(\equiv \mathrm{C}-\mathrm{H})\end{array}$ & & $\begin{array}{l}2100(\mathrm{w}) \\
3280\left(\mathrm{~s}, v_{\equiv \mathrm{C}-\mathrm{H}}\right)\end{array}$ & 486.4 & 494.8 & $\begin{array}{l}245(4.75) \\
256(4.79)\end{array}$ \\
\hline IIIa & $\begin{array}{l}0.46\left(\mathrm{Sn}-\mathrm{CH}_{3}\right) \\
J_{\mathrm{Sn}-\mathrm{H}}=55 \mathrm{~Hz}\end{array}$ & $\begin{array}{c}9.1 \\
J_{\mathbf{P t}-\mathbf{P}} \\
=2354 \mathrm{~Hz}\end{array}$ & $2100(s)$ & $\begin{array}{l}486.4 \\
\left(\mathrm{Pt}_{4 \mathrm{f}}\right.\end{array}$ & $\begin{array}{r}494.8 \\
72.6 \\
75.9)\end{array}$ & $\begin{array}{l}269(4.45) \\
289(4.66) \\
328(4.63) \\
337(\text { sh, } 4.61)\end{array}$ \\
\hline IIIb & $\begin{array}{l}0.46\left(\mathrm{Sn}-\mathrm{CH}_{3}\right) \\
J_{\mathrm{Sn}-\mathrm{H}}=55 \mathrm{~Hz}\end{array}$ & 16.5 & $2100(\mathrm{~s})$ & $\begin{array}{l}486.5 \\
\qquad\left(\mathrm{Pd}_{3 \mathrm{~d}}\right.\end{array}$ & $\begin{array}{l}494.9 \\
337.8 \\
343.0)\end{array}$ & $\begin{array}{l}247(4.48) \\
294(4.70) \\
308(\text { sh, 4.68) }\end{array}$ \\
\hline $\begin{array}{l}\text { IV } \\
\text { V }\end{array}$ & & & $\begin{array}{l}2200(w) \\
2200(w)\end{array}$ & $\begin{array}{l}486.6 \\
486.6\end{array}$ & $\begin{array}{l}494.9 \\
494.9\end{array}$ & \\
\hline
\end{tabular}

a Chemical shifts from internal $\mathrm{PPh}_{3}$ (positive shifts to low field).

b Measured on sticky tape and with reference to the carbon $1 \mathrm{~s}$ line (taken to be $285.0 \mathrm{eV}$ ) of each samples.

c In hexane.

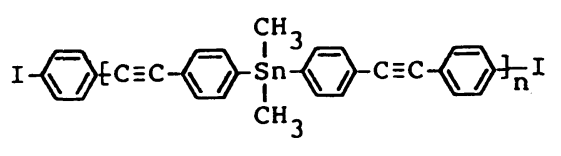

IVa

The polymer $\mathbf{V}$ was prepared by the oxidative coupling of ethynyl groups. The $\mathrm{Sn}-\mathrm{C}$ bond in the monomer $\mathbf{I}$ is stable toward the oxidant derived from cuprous chloride, tetramethylethylenediamine and oxygen, ${ }^{7}$ and the coupling reaction of ethynyl groups proceeds smoothly at room temperature to give polymer $\mathbf{V}$ in an almost quantitative yield. The polymers IV and $\mathbf{V}$ are insoluble in common organic solvents except hot bromobenzene and the insolubility prevented purification by column chromatography.

The polymers prepared in the present work were characterized by elemental analyses and spectroscopic methods. The spectral data are summarized in Table I along with the tin monomer I. The ${ }^{31} \mathrm{P}$ NMR spectra indicate ${ }^{4}$ trans-configuration of $\mathrm{Pt}$ and $\mathrm{Pd}$ in the polymer II. ESCA spectra revealed tha the metals retain the same oxidation state in the polymer as in the monomer, showing that no unusual reaction occurs. In UV spectra, the appearance of absorptions at longer wavelengths than $300 \mathrm{~nm}$ in the polymers suggests $d_{\pi}-p_{\pi}$ interaction between the transition metal and acetylenic system. However, hardly any effect of tin atom on the conjugation of polymer backbone was observed. The polymers IIIV form thin films when cast from their solutions.

\section{REFERENCES}

1. See, for example, J. E. Sheats, C. U. Pittman, Jr., and C. E. Carraher, Jr., Chem. Br., 20, 709 (1984).

2. C. E. Carraher, Jr., "Interfacial Synthesis," Vol. II, F. Millich and C. E. Carraher, Jr., Ed., Marcel Dekker, New York, N. Y., 1977, p 366.

3. W. P. Neumann and B. Schneider, Justus Liebigs Ann. Chem., 707, 20 (1967).

4. N. Hagihara, K. Sonogashira, and S. Takahashi, Adv. Polym. Sci., 41, 149 (1981).

5. S. Takahashi, M. Kariya, T. Yatake, K. Sonogashira, and N. Hagihara, Macromolecules, 11, 1063 (1978).

6. S. Takahashi, Y. Kuroyama, K. Sonogashira, and N. Hagihara, Synthesis, 627 (1980).

7. S. Takahashi, E. Murata, K. Sonogashira, and N. Hagihara, J. Polym. Sci., Polym. Chem. Ed., 18, 661 (1980). 